\title{
Patient-reported outcomes in Canadian cancer research
}

Cite as: CMAJ 2021 November 15;193:E1739-40. doi: 10.1503/cmaj.210770

T hese days, medical researchers may take the inclusion of patient perspectives in clinical science for granted, but it was the result of a long, multifaceted process that unfolded over several decades. ${ }^{1}$ In this article, I explore 1 aspect of the incorporation of patient perspectives into clinical research in Canada - the introduction of patient-reported outcome measures to cancer trials.

Before 1980, if cancer trials assessed the quality of life of patients, it was from the perspective of physicians and nurses who summarized their impressions of highly subjective patient experiences, like pain, fatigue and nausea. ${ }^{2}$ In the early 1980 s, clinicians attempted to introduce changes into cancer care and management, informed by evidence from patients. ${ }^{3} \mathrm{Clin}$ ical researchers thought that patient perceptions could help account for differences in reported toxicities across various treatment regimens, and that perceptions of toxicity played a role in a patient's quality of life and, possibly, their survival. In this context, researchers in the emerging field of psychosocial oncology started the trend toward greater patient participation in treatment decisions and an increased acceptance of patient feedback in cancer care. ${ }^{4}$ Research in psychosocial oncology featured patient-reported outcome

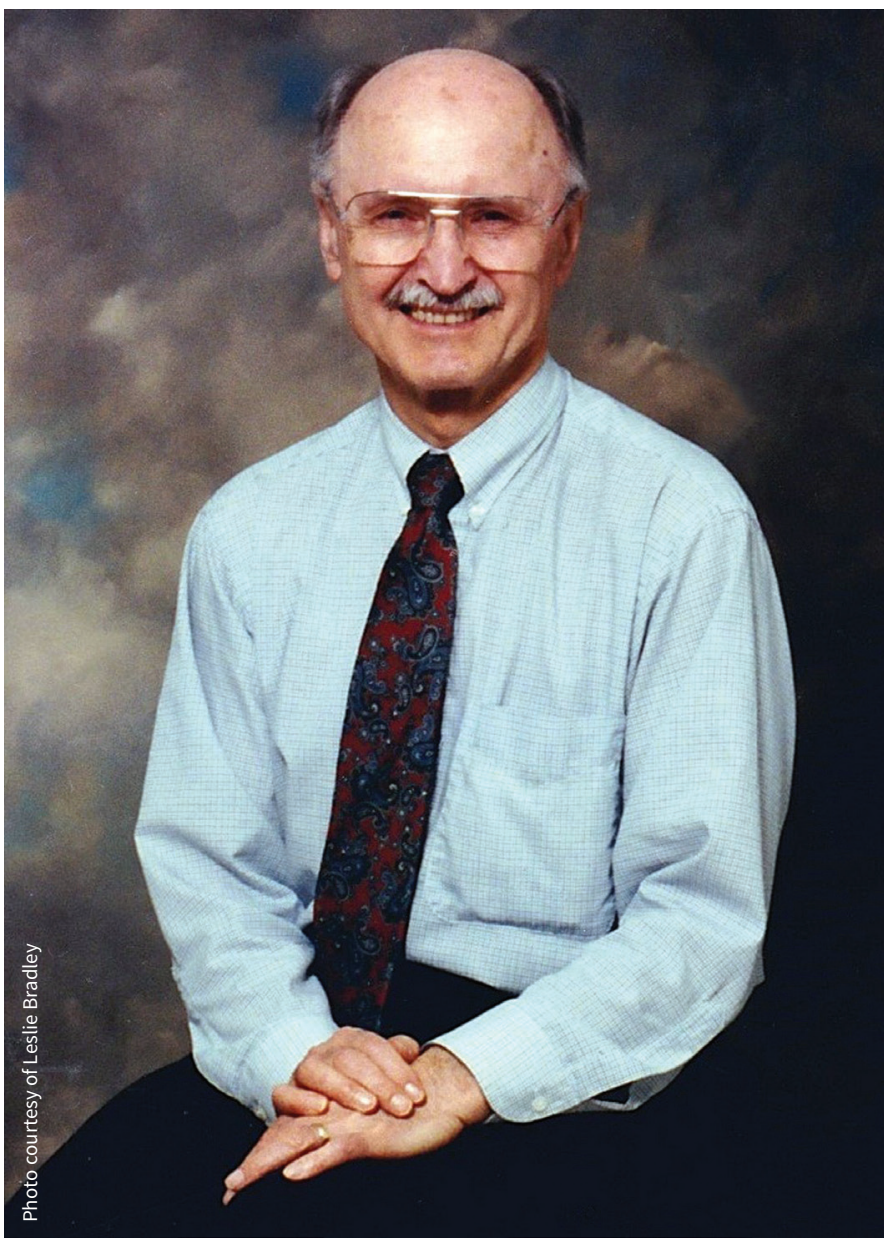

1982 national cooperative clinical trial comparing combination chemotherapy to best supportive care for patients with advanced nonsmall cell lung cancer. ${ }^{6}$ The National Cancer Institute of Canada $(\mathrm{NCIC})$ activated this multicentre clinical trial, BR-5, in early 1983, which included a quality-of-life questionnaire that was completed at regular intervals by patients at some of the participating centres. The questionnaire, known as the Functional Living Index: Cancer, had been developed by medical oncologist Harvey Schipper and his colleagues in Winnipeg. ${ }^{7}$ Initially informed by patient interviews, the index evaluated psychologic and social functioning, as well as physical health.

Unfortunately, in the BR-5 trial, results on the quality-oflife data were deemed uninterpretable because fewer than $25 \%$ of the expected questionnaire forms were

measures as adjuncts to biomedical measures in clinical trials to make their analyses less open to interpretation.

In 1981, Walter Spitzer and collaborators at the McGill Cancer Centre developed a standardized tool known as the Quality of Life Index, based on advice from both health professionals and lay people, including patients. ${ }^{5}$ An alternative approach that involved a patient self-report questionnaire was used in a completed. ${ }^{8}$ Concerned that Canada would abandon patient self-reports in cancer research, Dr. David Osoba, a member of the subcommittee on lung carcinoma within the $\mathrm{NCIC}$ Clinical Trials Group sought advice from researchers at the United States National Cancer Institute and the European Organization for Research and Treatment of Cancer (EORTC). The shift to including qualityof-life assessments in cancer research 
was an international phenomenon, and he reasoned that others would have found ways to deal with low questionnaire completion rates, as well as skeptical researchers unsure of how to interpret limited data.

As it turned out, policy changes at the US Food and Drug Administration (FDA) were effective in motivating researchers at the National Cancer Institute to include quality-of-life measures, such as patient self-reports, in clinical trials. The FDA Oncology Drugs Advisory Committee mandated that all regulatory trials contain both survival and qualityof-life measures. ${ }^{9}$ This development diminished the pushback from oncologists who opposed measuring healthrelated quality of life (HRQOL) as too complex and costly. At the same time, the EORTC began validating its HRQoL questionnaire, known as the EORTC QLQ-C30. ${ }^{10}$ Considering this, Dr. Osoba approached Dr. Joseph Pater, director of the NCIC Clinical Trials Group (CTG, currently the Canadian Cancer Trials Group) and proposed forming a committee to determine the potential clinical utility of HRQoL data. ${ }^{11}$

Dr. Osoba received positive feedback from several NCIC colleagues about the need to study the effects of both the disease and the treatment on the patient's life. To reach a broader professional consensus, the NCIC-CTG convened an international symposium, "Measurement of Quality of Life in Clinical Trials," in April 1986. ${ }^{11}$ Most symposium participants agreed that collaborative efforts in HRQoL studies, coordinated by the NCIC-CTG, were necessary. Consequently, the working group established national and international links with like-minded investigators and formed a standing committee in 1987 , which recommended that quality-of-life data collection be incorporated into several trials. ${ }^{11}$ The $\mathrm{NCIC}-\mathrm{CTG}$ received input regarding the best available and validated instruments to measure HRQoL parameters from the EORTC and the National Cancer Institute. The NCIC-CTG opted for using the EORTC-designed QLQ-C30 assessment instrument in most clinical trials. In addition to facilitating incorporation of HRQoL instruments into clinical trials, members of the Quality of Life Committee explored methodologic and statistical issues of quality-of-life measurement outcomes, work that is still relevant. In 1989, the $\mathrm{NCIC}-\mathrm{CTG}$ introduced a policy requiring all protocols for Phase III clinical trials to include a statement on the expected impact of treatment on patient quality of life. ${ }^{12}$ This policy helped Health Canada and other regulatory authorities evaluate the benefits and harms of treatments for patients more fully. Going forward, the assessment of HRQoL made clinical research more evidence-based and truly patientoriented. Since the 1990s, members of the NCIC-CTG Quality of Life Committee have been leaders and active participants in international efforts to enhance the implementation and interpretation of patient-reported outcomes in clinical trials.

Ultimately, the role of patients in cancer research has expanded beyond completing quality-of-life assessments as a reflection of the individual patient's wellbeing to the involvement of patients in policy-making to address societal issues concerning more humane health care.

\section{Fedir Razumenko PhD}

University of Calgary, Calgary, Alta.

\section{References}

1. Duffin J. History of medicine: a scandalously short introduction. 3rd ed. Toronto: University of Toronto Press, 2021.
2. Prutkin JM, Feinstein AR. Quality-of-life measurements: origin and pathogenesis. Yale J Biol Med 2002;75:79-93.

3. Osoba D. Interview with D. Osoba. Interviewed by Fedir Razumenko [academic oral history]. Vancouver: 2019 June 3.

4. Holland JC, Breitbart WS, Jacobsen PB, et al., editors. Psycho-oncology. 3rd ed. Oxford (UK): Oxford University Press; 2015.

5. Spitzer WO, Dobson AJ, Hall J, et al. Measuring the quality of life of cancer patients: a concise QL-index for use by physicians. J Chronic Dis 1981;34:585-97.

6. Rapp E, Pater JL, Willan A, et al. Chemotherapy can prolong survival in patients with advanced non-small-cell lung cancer: report of a Canadian multicenter randomized trial. J Clin Oncol 1988;6:633-41.

7. Schipper H, Clinch J, McMurray A, et al. Measuring the quality of life of cancer patients: the Functional Living Index-Cancer: development and validation. J Clin Oncol 1984;2:472-83.

8. Osoba D. Correspondence from D. Osoba to J.L. Pater. Toronto: 1985 Oct. 8.

9. Johnson JR, Temple R. Food and Drug Administration requirements for approval of new anticancer drugs. Cancer Treat Rep 1985;69:1155-9.

10. Aaronson N. Interview with N. Aaronson. Interviewed by F. Razumenko [academic oral history] The Hague (Netherlands): 2020 June 1.

11. Osoba D. Effect of cancer on quality of life. Boca Raton (FL): CRC Press; 1991.

12. Sadura A, Pater J, Osoba D, et al. Quality-of-life assessment: patient compliance with questionnaire completion. J Natl Cancer Inst 1992; 84:1023-6.

This article has been peer reviewed.

Competing interests: Fedir Razumenko reports funding from the Alberta Medical Foundation and the Nova Scotia Health Research Foundation's Associated Medical Services.

Content licence: This is an Open Access article distributed in accordance with the terms of the Creative Commons Attribution (CC BY-NC-ND 4.0) licence, which permits use, distribution and reproduction in any medium, provided that the original publication is properly cited, the use is noncommercial (i.e., research or educational use), and no modifications or adaptations are made. See: https://creativecommons.org/ licenses/by-nc-nd/4.0/

Funding: This research was funded by grants from the Alberta Medical Foundation and the Nova Scotia Health Research Foundation's Associated Medical Services. 